\title{
Epithelial Membrane Protein 2 Is a Prognostic Indictor for Patients with Urothelial Carcinoma of the Upper Urinary Tract
}

\author{
Yi-Wen Wang, ${ }^{*}$ Wei-Ming Li, ${ }^{\dagger}$ Wen-Jeng Wu, ${ }^{\dagger \ddagger \S}$ Chee-Yin Chai, $"$ Tsuey-Yu Chang, ${ }^{\|}$Yin Sun, ${ }^{* *}$ Chih-Jen Cheng, ${ }^{\dagger \dagger}$ \\ Yow-Ling Shiue, ${ }^{\ddagger \ddagger}$ Shu-Jem Su, ${ }^{\S}$ Hong-Lin Cheng, ${ }^{\text {बा H}}$ Hsiao-Sheng Liu, ${ }^{* \dagger \dagger}$ and Nan-Haw Chow ${ }^{*, * *\|\| \|}$
}

\begin{abstract}
From the Institute of Basic Medical Sciences, ${ }^{*}$ the Departments of Parasitology, ${ }^{\|}$Microbiology and Immunology, ${ }^{\dagger \dagger}$ Urology, ${ }^{\mathbf{9}}$ and Pathology, ${ }^{\|\|}$and the Institute of Molecular Medicine, ** College of Medicine, National Cheng Kung University, Tainan; the Departments of Urology ${ }^{\dagger}$ and Pathology, ${ }^{\natural}$ Kaohsiung Medical University Hospital, the Department of Urology, ${ }^{\ddagger}$ Kaohsiung Municipal Hsiao-Kang Hospital, the Department of Urology, ${ }^{\S}$ Faculty of Medicine, College of Medicine, Kaohsiung Medical University, Kaohsiung; the Institute of Biomedical Sciences ${ }^{\ddagger \ddagger}$ National Sun Yan-Sen University, Kaohsiung; and the Department of Medical Technology, ${ }^{\S \S}$ Fooyin University, Kaohsiung Hsien, Taiwan
\end{abstract}

\author{
Accepted for publication \\ May 28, 2013. \\ Address correspondence to \\ Nan-Haw Chow, M.D., \\ Department of Pathology, \\ National Cheng Kung Univer- \\ sity Hospital, 138 Sheng-Li \\ Road, Tainan 70428, Taiwan; or \\ Hsiao-Sheng Liu, Ph.D., Depart- \\ ment of Microbiology and \\ Immunology, College of Medi- \\ cine, National Cheng Kung \\ University, Tainan 701, Taiwan. \\ E-mail: chownh@mail.ncku. \\ edu.twora713@mail.ncku. \\ edu.tw.
}

\begin{abstract}
Upper urinary tract urothelial carcinoma is a relatively uncommon disease and is diagnosed more frequently at advanced stages. The prognosis of these patients mainly has been related to tumor stage and grade. As a result, the definition of prognostic indicators enabling precise patient selection is mandatory for neoadjuvant or adjuvant therapies. The epithelial membrane protein (EMP2) was identified as one of the up-regulated genes by isoflavones. EMP2 overexpression suppressed foci formation, anchorage-independent growth in vitro, and tumorigenicity in severe combined immunodeficiency mice (all $P<0.05$ ). In addition, a cross-talk between EMP2 and integrins $\alpha \mathrm{V}$ and $\beta 3$ was shown in the regulation of cell adhesion and migration. Higher EMP2 expression was associated with a better progression-free survival $(P=0.008)$ and cancer-related death $(P<0.001)$. EMP2 was identified as a tumor-suppressor gene in urinary tract urothelial carcinoma and may be an innovative co-targeting candidate for designing integrin-based cancer therapy. (Am J Pathol 2013, 183: 709-719; http:// $d x$. doi.org/10.1016/j.ajpath.2013.05.015)
\end{abstract}

Urothelial carcinoma (UC), which tends to occur multifocally in the entire urothelium of the renal pelvis, ureter, bladder, and proximal urethra, was the fourth most common cancer among men in the United States in 2010. ${ }^{1}$ Most UC (90\% to $95 \%$ ) occurs in the urinary bladder, with low incidence (5\% to $10 \%$ ) in the upper urinary tract (renal pelvis and ureter, UUT-UC). ${ }^{2}$ An unusually high incidence of UUT-UC has been documented in Taiwan and represents $20 \%$ to $25 \%$ of UC. ${ }^{3} \mathrm{UC}$ can be classified into two main phenotypic variants: non-muscle invasive (Ta, T1, and Tis) and muscle invasive (T2, T3, and T4). Currently, clinical stage and pathologic grade are the primary prognostic factors in these patients; although an individual difference in the biological potential still is observed, even in patients with the same stage or grade. ${ }^{4}$ UUT-UC shares many similarities with bladder cancer; however, it is a higher grade and stage disease than bladder cancer. ${ }^{5}$ Thus, it is important to identify prognostic markers in the selection of patients who have a higher risk of progression.

Epithelial membrane protein 2 (EMP2) is one member of the transmembrane superfamily, which contains three major families: peripheral myelin protein 22 , the connexins, and the tetraspanins. EMP2 belongs to the peripheral myelin protein 22 family, which consists of at least six other members: PMP22, EMP1, EMP3, PERP, brain cell membrane protein 1, and MP20. ${ }^{6,7}$ EMP2 is predicted to contain two extracellular domains, a small cytoplasmic tail, and three putative $\mathrm{N}$-linked glycosylation sites. EMP2 is reported to be involved

Supported by grants NSC 92-2320-B-006-071, NSC 93-2320-B-006025, NSC 94-2320-B-006-007, and NSC 98-2320-B-006-022-MY3 from the National Science Council, Taiwan; and EX99-9930BI from the National Health Research Institutes, Taiwan. 
in cell proliferation and cell-cell interactions. ${ }^{6,8}$ EMP2 has been identified as a tumor-suppressor gene for B-cell lymphoma ${ }^{9}$ and nasopharyngeal carcinoma. ${ }^{10}$ The increased EMP2 expression in lymphoma cells was associated with reduced in vivo tumorigenicity and increased apoptosis in the absence of growth factor. Recent studies, however, have reported that diabodies targeting EMP2 suppress the tumorigenicity of human endometrial cancer cells in vitro. ${ }^{11}$ In addition, EMP2 appears to be a novel biomarker or therapeutic target for endometrial and ovarian cancers. ${ }^{12,13}$ In terms of regulatory networks, the membrane protein regulates the trafficking of integrins, caveolins, glycosylphosphatidyl inositol-linked proteins, and major histocompatibility complex class I proteins. ${ }^{14}$ EMP2 is physically associated with, and modulates the function of, certain integrin isoforms in physiological settings, such as blastocyst implantation, and in model settings of cellular proliferation, invasion, adhesion, and metastasis. ${ }^{15}$

Many in vitro and in vivo experiments have provided evidence that phytochemicals in fruits and vegetables affect the initiation, promotion, and progression of human cancers. ${ }^{16}$ Polyphenolic compounds are one of the largest and most ubiquitous groups of phytochemicals that possess anticancer effects (eg, genistein). ${ }^{17}$ In vitro, soy isoflavones dosedependently inhibit the growth (G2-M cell-cycle arrest), yet induce tumor angiogenesis and cancer cell apoptosis. ${ }^{18} \mathrm{We}$ previously showed that genistein, daidzein, and biochanin-A may have different anticancer effects in the range of human urine excretion ${ }^{19}$ and induce an anti-angiogenesis effect on human bladder cancer in vitro. ${ }^{20}$ Here, we describe the discovery of EMP2 in a molecular profiling experiment of the effect of isoflavone on $\mathrm{UC}^{21}$ and investigate its biological basis and prognostic implication in patients with UUT-UC.

\section{Materials and Methods}

\section{Cell Lines}

Cell lines used in this study were purchased from the American Type Culture Collection (Manassas, VA). The E7 (immortalized uroepithelial cell), RT4, and TSGH8301 UC cells were maintained in F12, McCoy's 5A, and Dulbecco's modified Eagle's medium (DMEM) (Invitrogen, Carlsbad, CA), respectively, as described in detail previously. ${ }^{19}$ The BFTC909 cell line was derived from the sarcomatoid component of a grade III UC of the renal pelvis and shows a fibroblastic growth pattern. The remaining UC cell lines were derived from the urinary bladder.

\section{Forward Subtraction of Suppression Subtractive Hybridization and Function Assay}

In the present study, a suppression subtractive hybridization (SSH) approach was used to identify genes induced by isoflavones in vitro. SSH was performed on RT4 cells using the PCR-Select cDNA subtraction kit (Clontech, BD Biosciences, Palo Alto, CA) according to the manufacturer's recommendations.
When $80 \%$ confluence was reached, the RT4 cells were washed twice with PBS and then cultured with medium containing $0.5 \%$ fetal bovine serum (McCoy's 5A; Invitrogen) (serum starvation) with or without $10 \mu \mathrm{g} / \mathrm{mL}$ genistein, daidzein (Calbiochem, San Diego, CA), and biochanin A (Sigma-Aldrich, St. Louis, MO) for 24 hours. In the present study, a SSH approach was used to identify genes induced by isoflavones in vitro. SSH was performed on RT4 cells using a PCR-Select cDNA Subtraction kit (Clontech, BD Biosciences) according to the manufacturer's recommendations.

The forward SSH cDNA library was constructed using RT4 cells treated with isoflavones as the tester and RT4 cells without treatment as the deriver. Total RNA was extracted using TRIzol (Invitrogen, Carlsbad, CA), and poly(A) ${ }^{+}$RNA was isolated using a commercial kit (Qiagen, Valencia, CA). First-strand cDNA was synthesized from $2 \mu \mathrm{g}$ of poly $(\mathrm{A})^{+}$RNA using oligo(dT) priming with reverse transcriptase (cloned avian myeloblastosis virus; Clontech), and second-strand cDNA was generated using T4 DNA polymerase (Clontech). The restriction endonuclease RsaI was used to obtain short and bluntended fragments. Two tester populations were generated with different adaptors for subsequent PCR amplification. The first hybridization was performed using each tester population, and the driver hybridization kinetics led to equalization and enrichment of differentially expressed sequences. The second hybridization generated templates for PCR amplification from differentially expressed sequences between the tester and driver populations. Twenty-seven PCR cycles were run using a cDNA polymerase mix (Advantage; Clontech). The subtracted fragments then were inserted into a thymidine-adenine cloning vector (pGEM-T-easy; Promega, Madison, WI). The transformants carrying subtracted cDNA fragments were isolated from agar plates and analyzed with an autosequencer (ABI Prism; Applied Biosystems, Foster City, CA) to check the fragment sequence. The identity of each sequence was verified using the Basic Local Alignment Search Tool search program (http://www.blast.ncbi.nlm.nih.gov).

\section{Constructing EMP2 Promoter and Luciferase Reporter Assays}

The promoter region $(-1420 \mathrm{bp}$ to $+268 \mathrm{bp})$ of $E M P 2$ was amplified from RT4 cancer cells using PCR with customdesigned primers: sense, 5'-CCGCTCGAGTATAGCAACCAGACCTCACCCT- ${ }^{\prime}$ (XhoI restriction site is in italics and antisense, 5'-CCCAAGCTTCCCGTTACTGTCACCAATTCC- $3^{\prime}$ (HindIII restriction site is in italics). The products were cloned into pGEM-T-easy and then subcloned into promoterless luciferase vector pGL3-basic. Briefly, cells were cultured in a 12-well culture dish and transfected with $1.9 \mu \mathrm{g} /$ well pGL3-basic or pGL3-EMP2 promoter and $0.1 \mu \mathrm{g} / \mathrm{well}$ thymidine kinase promoter-Renilla luciferase reporter plasmid using a reagent (Lipofectamine 2000; Invitrogen). Six hours later, the medium in the dishes was replaced with medium containing $10 \%$ fetal calf serum or nonserum with or without $10 \mu \mathrm{g} / \mathrm{mL}$ isoflavone treatment. Luciferase activity was 
determined after 24 hours (Dual-Luciferase Reporter Assay System; Promega), in which equivalent amounts of protein lysates $(20 \mu \mathrm{L})$ were mixed with a reagent (Luciferase Assay Reagent II; Promega). The light signal emitted from luciferase in the extract was measured using a luminometer (Minilumate LB 9506; from Berthold Technologies, GmbH \& Co. KG, Bad Wildbad, Germany).

\section{Real-Time PCR Analysis}

Total RNA was isolated using TRIzol according to the manufacturer's instruction. Two microgram samples were reverse-transcribed to synthesize first-strand cDNA using oligo dT and Moloney murine leukemia virus reverse transcriptase (Promega). A real-time PCR system (LightCycler; Roche, Indianapolis, IN) and FastStart DNA Master SYBR Green I (Roche) labeling were used to measure the expression of target genes. The reaction first was run for 7 minutes to denature the DNA and activate the hot-start polymerase and then was followed by $40 \mathrm{PCR}$ cycles that consisted of denaturizing at $95^{\circ} \mathrm{C}$ for 10 seconds, annealing at $60^{\circ} \mathrm{C}$ for 5 seconds, and elongation at $72^{\circ} \mathrm{C}$ for 12 seconds in glass capillaries. The primers used were as follows: peptidylprolyl isomerase A forward: 5'-GTTTGCAGACAAGGTCCCA-3', peptidylprolyl isomerase A reverse: $5^{\prime}$-ACCCGTATGCTTTAGGATG-3'; EMP2 forward: 5'-TGCTGTTCATTGCCACCGT-3', EMP2 reverse: 5'-AGGCGATGCAGCAGAGA-3'; integrin $\alpha \mathrm{V}$ forward: 5'-CCAACTCCACATTGGTTACC- $3^{\prime}, \alpha \mathrm{V}$ reverse: $5^{\prime}$-CCAATTAGCACTATCAGCAG$3^{\prime}$; integrin $\beta 3$ forward: $5^{\prime}$-GAATGTGGCAGCTGTGTCTG$3^{\prime}, \beta 3$ reverse: $5^{\prime}$-CTTCTACCACATACAGGATGG- ${ }^{\prime}$; TBP forward: $5^{\prime}$-TTCGGAGAGTTCTGGGATTG-TA-3' ${ }^{\prime}$, and TBP reverse: 5'-TGGACTGTTCACTCTTGGC-3'.

\section{Stable Transfectant of EMP2-GFP}

Full-length EMP2 cDNA was amplified from HEK-293 cells using the following primers: 5'-GCGGAAGCTTGCCACCATGTTGGTGCTTCTTGCTTTCATC-3' (HindIII cutting site and translation start site are in italics) and $5^{\prime}$ CGGGATCCTTGCGCTTCCTCAGTATCAGG-3' (BamHI cutting site is in italics), and cloned into pEGFP-N1 vector (Clontech), in which an EGFP tag was incorporated into the C-terminus of the expressed protein. The TSGH8301 cells were stably transfected with pEGFPN1-EMP2 or pEGFPN1 using a reagent (Lipofectamine 2000) for 24 hours. They were subcultured at a dilution of 1:5 in medium containing 600 $\mu \mathrm{g} / \mathrm{mL}$ G418 (Calbiochem) for selection. Plasmid-containing colonies were pooled, stable transfectants were generated, and the colonies (TSGH8301/EMP2-2 and TSGH8301/EMP2-3) then were isolated and propagated for subsequent analysis.

\section{The shRNA Transfection}

The shRNA transfection was performed to examine the effect of function loss for specific genes. In addition to knockdown of
EMP2, we used pSUPER (OligoEngine, Seattle, WA)/green fluorescent protein (GFP) (control group), pSUPER-hEMP22/GFP, pSUPER-hEMP2-4/GFP, pSUPER-hEMP2-2/Hyg, and pSUPER-hEMP2-4/Hyg(Hygromycin B) (kindly provided by W.T. Chang, PhD, Department of Biochemistry and Molecular Biology, National Cheng Kung University). To knock down the integrin $\beta 3$ or $\alpha \mathrm{V}$ shRNA interference pLKO.1-sh integrins $\beta 3$ (clone A1 sequence:, 5'-CCGGCATTATGTTTACAGAGGACAACTCGAGTTGTCCTCTGTAAACATAATGTTTTT- $3^{\prime}$ and $\mathrm{C} 1$ sequence: $5^{\prime}$-CCGGCCCTGTTACAATATGAAGAATCTCGAGATTCTTCATATTGTAACAGGGTTTTT- $3^{\prime}$ ) and -sh integrin $\alpha \mathrm{V}$ (clone H1 sequence: 5'-CCGGGCCTTACAAATACAACAACAACTCGAGTTGTTGTTGTATTTGTAAGGCTTTTTG-3', and G1 sequence: 5'-CCGGCGAGGGAAGTTACTTCGGATTCTCGAGAATCCGAAGTAACTTCCCTCGTTTTTG-3') were from the National RNAi Core Facility (Taipei, Taiwan), TSGH8301 or TSGH8301/EMP2 stable cells were transfected with plasmid pLKO.1-sh integrin $\beta 3$ or -sh integrin $\alpha \mathrm{V}$, pSUPER-hEMP2, or a control plasmid using a reagent (PolyJet DNA Transfection Reagent; SignaGen Laboratories, Rockville, MD) according to the manufacturer's protocol.

Briefly, $5 \times 10^{5}$ cells were seeded into a $6-\mathrm{cm}$ cell culture dish and incubated in DMEM without antibiotics. The transfection reagent was diluted in $100 \mu \mathrm{L}$ of serumfree DMEM and incubated for 5 minutes at room temperature. The shRNA was diluted in $100 \mu \mathrm{L}$ of serumfree DMEM at the assigned concentrations. Mock transfection was performed in parallel using distilled water as the negative control. The cells then were incubated at $37^{\circ} \mathrm{C}$ in an incubator with $5 \% \mathrm{CO}_{2}$ for 6 hours. The medium was replaced with normal medium, and the cells were incubated for an additional 48 hours before protein extraction.

\section{Immunofluorescent Staining and Confocal Microscopy}

The cells were plated onto glass coverslips for 48 hours. After they had been treated with medium containing $1 \mu \mathrm{mol} / \mathrm{L}$ prewarmed endoplasmic reticulum marker (ER-Tracker Blue-White DPX; Invitrogen) for 40 minutes, the cells were washed and fixed with $4 \%$ paraformaldehyde for 20 minutes at room temperature and then plated onto glass coverslips for 48 hours. They then were fixed in $4 \%$ paraformaldehyde for 20 minutes at room temperature and stained with DAPI as nuclear counterstain for 10 minutes at room temperature. A laser-scanning confocal microscope (FluoView; Leica, Santa Barbara, CA) was used to evaluate the distribution and localization of proteins. To simultaneously distinguish GFP- and DAPI-labeled cells, samples were excited with argon and krypton lasers at 488 $\mathrm{nm}$ and $600 \mathrm{~nm}$, respectively. A total of 20 to 30 horizontal $(x, y)$ sections were obtained at $1-\mu \mathrm{m}$ intervals. In all experiments, cells were analyzed using a $63 \times$ oil immersion objective. 
Fluorescence Activated Cell Sorter Analysis for Cell-Cycle Distribution

A total of $10^{6}$ cells/dish were first seeded in DMEM containing fetal bovine serum and growth supplements, and collected by a brief trypsinization for flow cytometric analysis on the second day. Briefly, cells were suspended in $3 \mathrm{~mL}$ of $70 \%$ alcohol and incubated at $-20^{\circ} \mathrm{C}$ overnight. Then, they were centrifuged and incubated in $1 \mathrm{~mL}$ of propidium iodide working solution $(0.2 \mathrm{~mL}$ of $1 \mathrm{mg} / \mathrm{mL}$ propidium iodide, 0.2 $\mathrm{mL}$ of 5\% Triton X-100 (EMD Millipore Corporation, Billerica, MA), and $1.0 \mathrm{~mL}$ of $2 \mathrm{mg} / \mathrm{mL}$ RNase A in $8.6 \mathrm{~mL}$ PBS) at $4{ }^{\circ} \mathrm{C}$ in the dark for 30 minutes. The cell-cycle distribution was analyzed by a fluorescence activated cell sorter. The percentage of cells in each phase of the cell cycle was determined by ModFit LT cell-cycle analysis software version 2.0 (Verity Software House, Topsham, ME).

\section{Apoptosis Analysis}

The apoptosis status was measured by a Vybrant apoptosis assay kit \#2 (Invitrogen) according to the manufacturer's instructions. Briefly, cells were washed and suspended in $1 \times$ annexin-binding buffer to the density of $1 \times 10^{6}$ cells $/ \mathrm{mL}$ in a total volume of $100 \mu \mathrm{L}$. They were incubated with $5 \mu \mathrm{L}$ of Alexa Fluor-488 annexin V (Invitrogen) and $1 \mu \mathrm{L}$ of $100 \mu \mathrm{g} /$ $\mathrm{mL}$ propidium iodide solution at room temperature for 15 minutes. Then, $400-\mu \mathrm{L}$ annexin-binding buffer was incubated on ice and analyzed by a flow cytometer as soon as possible.

\section{Focus Formation Assay}

Two hundred TSGH8301 cells were seeded in a 10-cm Petri dish, and the medium was changed every 4 days. After 14 days, the cells were washed with $1 \times$ PBS twice, fixed with 4\% paraformaldehyde for 20 minutes at room temperature, and stained with Giemsa. Colonies with a diameter greater than $2 \mathrm{~mm}$ were counted.

\section{Anchorage-Independent Cell Growth}

Anchorage-independent cell growth was determined by analyzing the colony formation of the TSGH8301 cells in soft agar. A total of $3 \times 10^{3}$ cells/well were suspended in $0.35 \%$ agar in DMEM containing $10 \%$ fetal calf serum and plated on solidified agar $(0.7 \%)$ in a 6-well plate. After 14 days of culturing, the cells were stained with $0.005 \%$ crystal violet for 30 minutes, and colony formation (diameter, $>100 \mu \mathrm{m}$ ) was examined using laser-scanning confocal microscopy.

\section{Tumorigenicity Assay}

The severe combined immunodeficiency mouse xenograft model was used as previously described. ${ }^{4}$ The experimental protocol was approved by the National Cheng Kung University Institutional Review Board. Briefly, $1 \times$
$10^{7}$ cells were injected s.c. into the backs of 5- to 6-weekold female mice. The mice were monitored regularly for tumor formation, and the nodules were measured with calipers for their largest diameter and weight.

\section{Clinicopathologic Characteristics of Study Cases}

The study cohort was composed of archival material from 171 patients (91 men and 80 women; age range, 24 to 86 years; means $\pm \mathrm{SD}, 65.7 \pm 10.9$ years) with UUT-UC who underwent radical nephroureterectomy at the Department of Urology of Kaohsiung Medical University Hospital between January 1991 and December $2005 .^{22}$ The median follow-up period was 40 months (range, 1-192 months). Patients who received neoadjuvant chemotherapy were not included in this study.

The study protocol was approved by the Human Investigations Committee. All cases were reviewed for histologic grade according to the World Health Organization classification. ${ }^{23}$ Clinical staging was determined according to the Tumor-Node-Metastasis System of the Union Internationale Contre le Cancer $^{24}$ using a survey of the clinical details, image studies, and pathologic data.

\section{Immunohistochemical Staining}

The immunostaining procedure and interpretation have been described in detail previously. ${ }^{25}$ Briefly, tissue sections were incubated at $4{ }^{\circ} \mathrm{C}$ overnight with monoclonal anti-EMP2 (1:40 dilution) (GenWay Biotech, San Diego, CA) antibody raised against the membrane protein. The optimal dilution was determined by using human lung tissue as a positive control. A kit (Liquid DAB + Substrate kit K3468; Dako, Carpinteria, CA) was used for the immunohistochemical study. Peroxidase activity was visualized using an aminoethyl carbazole substrate kit (Zymed Laboratories, Inc., San Francisco, CA). The slides were counterstained with Mayer's hematoxylin for 1 minute, dehydrated, and then routinely mounted. Specific primary antibody was replaced with PBS in tissue sections used as negative controls.

All the tumor tissue in each case was evaluated comprehensively for scoring of the staining results. The reviewers (N.-H.C. and C.-Y.C.) were blinded to the clinical outcomes. Because there was no apparent difference in staining intensity, we used a two-scale scoring system for EMP2 based on the proportion of tumor cells stained. ${ }^{25}$ The positive expression indicates that more than $20 \%$ of tumor cells were stained, whereas a negative expression indicates that less than 20\% were stained for EMP2 antibody.

\section{Statistical Analysis}

The Student's $t$-test and analysis of variance were used for all analyses. Significance was set at a $P$ value of less than 0.05 . The association between EMP2 expression and clinicopathologic features was assessed using the $\chi^{2}$ test. The correlation 
between EMP2 expression patterns and patient survival was constructed according to the Kaplan-Meier method, followed by the log-rank test. Cox regression analysis was used to determine the hazard ratio of death from UC in association with clinicopathologic parameters. Statistical analyses were performed using SPSS statistical software version 17.0 (SPSS, Inc., Chicago, IL) and GraphPad Prism 5 (GraphPad Software, Inc., San Diego, CA).

\section{Results}

\section{Modulation of EMP2 Expression by Isoflavones}

A total of $154 \mathrm{SSH}$ clones were selected randomly and submitted for sequence analysis. The homology search using the Nucleotide-Nucleotide Basic Local Alignment Search Tool (BLASTN; National Center for Biotechnology Information) found $70(45.5 \%)$ unique gene sequences (Supplemental Table S1). ${ }^{21}$ Four of these genes have been reported to be up-regulated by isoflavones (Supplemental Table S1). ${ }^{26-29}$ One gene, EGR-1, was consistent with our earlier microarray profiling experiment. ${ }^{27}$ Thus, this gene list was thought to provide important candidate genes that deserve further investigation.

To confirm the prediction of $\mathrm{SSH}$, the expression of EMP2 was first measured using Northern blotting with SSH cloning fragments as probes. Isoflavone treatment induced 3.5 times higher EMP2 expression in RT4 cells (Supplemental Figure S1), which supports the notion that EMP2 is involved in isoflavone-induced growth arrest. ${ }^{30}$ In addition, no deletions or mutations were found using PCR-based direct sequencing (data not shown). When the EMP2 promoter construct was transfected transiently to TSGH8301 cells, 50 times higher luciferase activity $(P<0.05)$ was detected after $10 \mu \mathrm{g} / \mathrm{mL}$ isoflavone treatment for 48 hours (Figure 1A). We then examined the modulation of EMP2 RNA expression by genistein, the single most potent isoflavone component. Real-time PCR showed that EMP2 expression was dosedependently up-regulated from 2 to $10 \mu \mathrm{mol} / \mathrm{L} 6$ days after genistein treatment $(P=0.03$; two-way analysis of variance) (Figure 1B) and time-dependently up-regulated from 2 to 6 days after genistein treatment $(P=0.004$; one-way analysis of variance) (Figure 1C).

\section{Expression Pattern of EMP2 in Human Uroepithelial Cells and Establishment of EMP2 Stably Overexpressed Clones}

First, EMP2 expression was investigated in uroepithelial cell lines: E7 (immortalized), RT4 (grade 1), TSGH8301 (grade 2), TCCSUP, J82, BFTC-905, BFTC-909, T24, and 5637 (grade 3). Real-time PCR showed a trend toward an

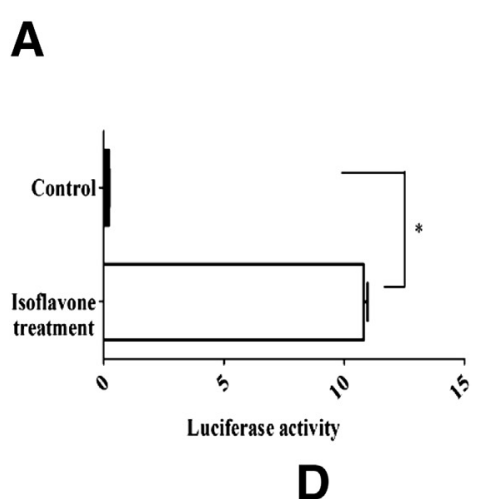

D

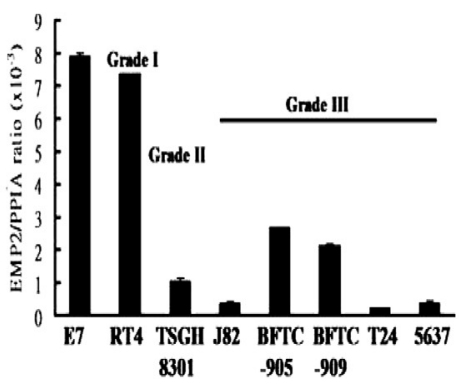

B

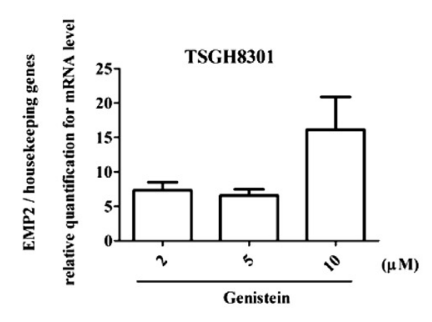

$\mathbf{E}$

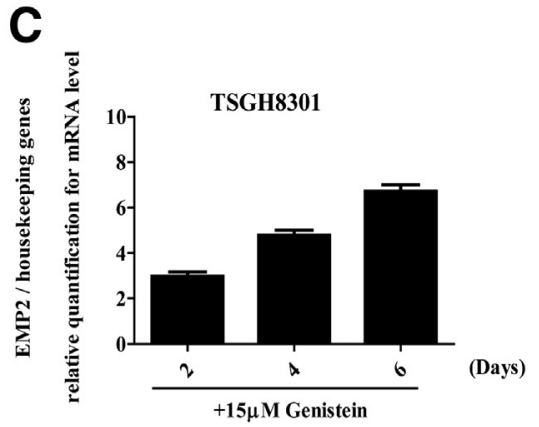

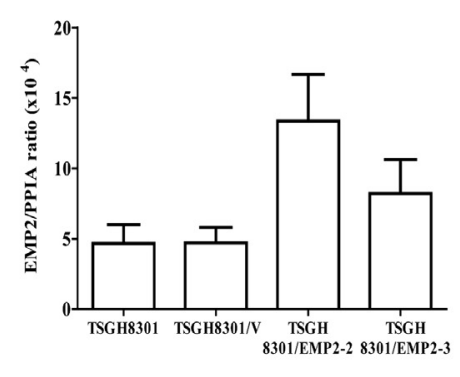

Figure 1 Modulation of EMP2 expression by isoflavones. A: The TSGH8301 cells were transfected with $5 \mu \mathrm{g}$ reporter gene constructs for 48 hours, and 0.25 $\mu \mathrm{g}$ thymidine kinase promoter-Renilla luciferase reporter plasmid vector served as an internal control. Firefly luciferase activity was measured after 48 hours, and normalized using Renilla luciferase activity. The values were compared with the means of each group. ${ }^{*}<0.05$, paired Student's $t$-test. Data are means \pm SD. B: EMP2 expression was dose-dependently up-regulated from 2 to $10 \mu \mathrm{mol} / \mathrm{L}$ (measured 6 days after genistein treatment). $P=0.03$ two-way analysis of variance. C: EMP2 also was time-dependently up-regulated after treatment with genistein from 2 to 6 days $(P=0.004$; one-way analysis of variance). D: Expression pattern of EMP2 in human uroepithelial cells. The RNA extracted using TRIzol was analyzed using real-time PCR; peptidylprolyl isomerase A (cyclophilin) was used as an internal control. There is a trend toward an inverse relationship between EMP2 expression and the histologic grades of cancer cell lines. E: TSGH8301 bladder cancer cells overexpressing EMP2 were cloned and measured for EMP2 expression using real-time PCR. The stable clone TSGH8301/ EMP2-2 has a higher level of EMP2 expression than in TSGH8301/EMP2-3 cells. 

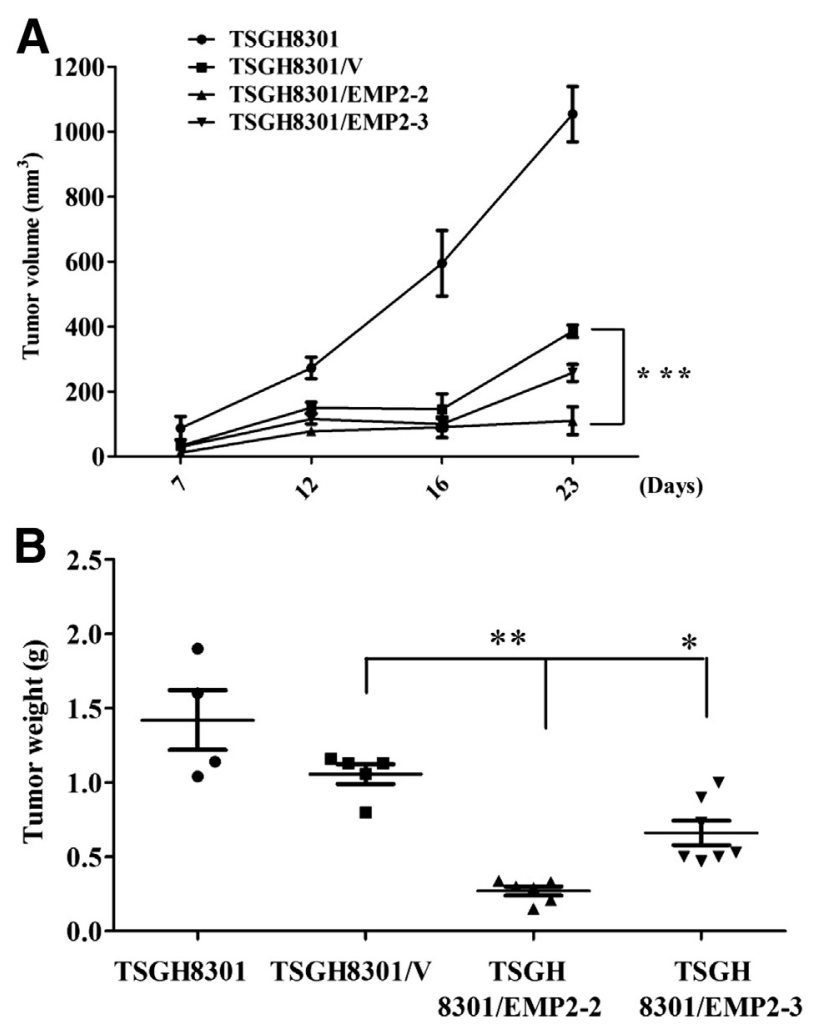

Figure 2 Tumorigenicity of EMP2 in vivo. Mice were transfected subcutaneously with TSGH8301 cells, TSGH8301/V cells, and two stable clones overexpressing EMP2 $\left(1 \times 10^{7}\right)$. A: The tumor mass was measured regularly for 23 days. Tumors that developed in mice transfected with TSGH8301/EMP2-2 cells were smaller than those that developed in mice transfected with TSGH8301/V cells. ${ }^{* * *} P<0.001$. The TSGH8301/E MP2-3 cells tended to have smaller tumors than that of TSGH8301/N $(P=0.06)$. B: The tumor weight was assessed 31 days after transfection. The means \pm SEM were obtained from eight severe combined immunodeficiency mice for each group. ${ }^{*} P<0.05,{ }^{*} P<0.01$, paired Student's $t$-test.

inverse relationship between EMP2 expression and the histologic grades of cancer cell lines (Figure 1D), which suggests that EMP2 may be a tumor suppressor in the progression of human urothelial cancer.

Among cancer cell lines tested, the most relevant cell lineBFTC909-was derived from the sarcomatoid UC of renal pelvis, a rare histology for UUT-UC. The cells also have mutated p53 (data not shown) and are resistant to transfection experiments. As a result, the TSGH8301 UC cell line was chosen to establish constitutively overexpressed clones (TSGH8301/EMP2-2 and TSGH8301/EMP2-3) using EMP2-expressing reporter plasmid (EGFP) fusion plasmid for experiments in vitro. EMP2 mRNA expression was higher in stable clones (TSGH8301/EMP2-2, TSGH8301/EMP2-3) than in control cells (TSGH8301/V) examined using real-time PCR (Figure 1E).

\section{The Tumorigenic Effect of EMP2 in Vivo}

To examine the biological significance of EMP2 in vivo, 5- to 6-week-old female severe combined immunodeficiency mice were transfected s.c. with TSGH8301, TSGH8301/V, TSGH8301/EMP2-2, or TSGH8301/EMP2-3 cells $\left(1 \times 10^{7}\right)$. There was no significant difference in tumorigenicity between TSGH8301/V and TSGH8301/EMP2-3 cells (lower level of EMP2 expression $)(P=0.06)$. However, mice transfected with TSGH8301/E MP2-2 cells (higher level of EMP2 expression) developed smaller tumors than those transfected with TSGH8301/V cells $(P<0.001)$. A significant difference also was observed between TSGH8301/EMP2-2 and TSGH8301/EMP2-3 $(P=0.02)$ (Figure 2A). The mice transfected with TSGH8301/EMP2 cells developed tumors
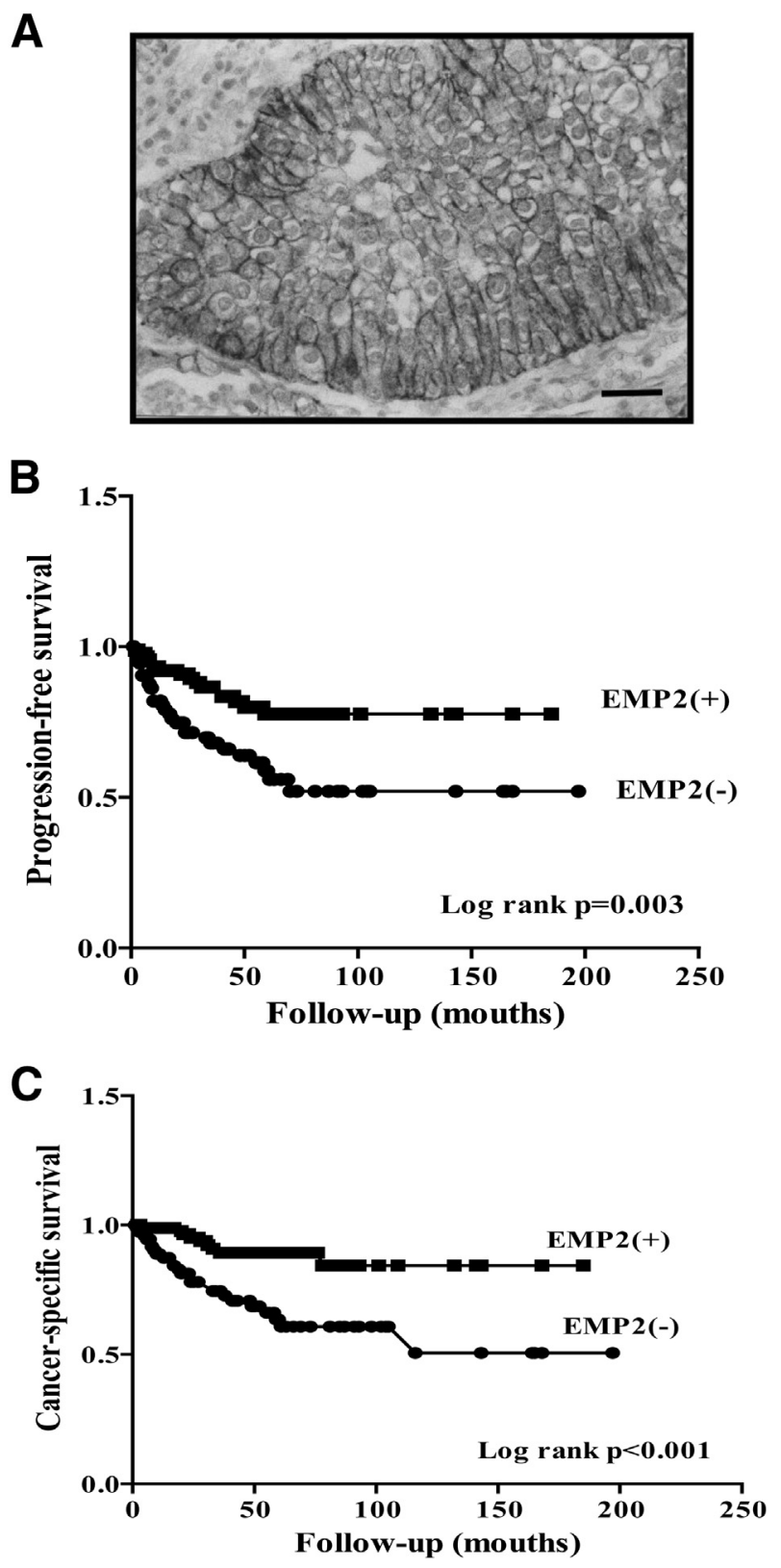

Figure 3 Expression of EMP2 and its prognostic significance in urothelial carcinoma. A: Immunohistochemical staining showed membranous expression of EMP2 in high-grade urothelial carcinoma cells of the ureter $(400 \times)$. Both progression-free (B) and cancer-specific (C) survival in relation to EMP2 expression were analyzed by Kaplan-Meier survival analysis. 
Table 1 Prognostic Significance of Clinicopathologic Indicators and EMP2 Status in Relation to Clinical Outcome (Univariate and Multivariate Cox Regression Analysis)

\begin{tabular}{|c|c|c|c|c|c|c|}
\hline \multirow[b]{3}{*}{ Variables } & \multicolumn{3}{|c|}{ Progression-free survival } & \multicolumn{3}{|c|}{ Cancer-specific survival } \\
\hline & \multirow{2}{*}{$\begin{array}{l}\text { Univariate } \\
\text { analysis, } P\end{array}$} & \multicolumn{2}{|l|}{ Multivariate analysis } & \multirow{2}{*}{$\begin{array}{l}\text { Univariate } \\
\text { analysis, } P\end{array}$} & \multicolumn{2}{|l|}{ Multivariate analysis } \\
\hline & & $\mathrm{HR}(95 \% \mathrm{CI})$ & $P$ & & $\mathrm{HR}(95 \% \mathrm{CI})$ & $P$ \\
\hline Sex & 0.925 & & & 0.839 & & \\
\hline Tumor location & 0.080 & & & 0.191 & & \\
\hline Lymph node status & $<0.001$ & $8.157(3.404-19.544)$ & $<0.001$ & $<0.001$ & $0.224(0.102-0.409)$ & $<0.001$ \\
\hline EMP2 status & 0.003 & $0.419(0.221-0.794)$ & 0.008 & $<0.001$ & $13.025(4.595-36.920)$ & $<0.001$ \\
\hline
\end{tabular}

Bold text indicates statistical significance.

$\mathrm{CI}$, confidence interval; $\mathrm{HR}$, hazard ratio.

that weighed significantly less than those developed by TSGH8301 control mice $(P<0.05$ and $P<0.01)$ (Figure 2B).

\section{Expression of EMP2 and its Prognostic Significance in UUT-UC}

Immunohistochemical staining of primary UC revealed membranous expression of EMP2 on cancer cells (Figure 3A). To determine the association of EMP2 with clinicopathologic characteristics, immunohistochemistry was performed on 171 UUT-UC patients (Supplemental Table S2). No significant relationship was found between EMP2 expression status and $\mathrm{pT}$ stage $(P=0.575)$ or tumor grade $(P=0.666)$. However, loss of EMP2 expression was associated significantly with disease progression $(P=0.007$, $\chi^{2}$ test $)$ and cancer-related death rates $\left(P=0.001, \chi^{2}\right.$ test $)$.

In terms of prognostic indicators, multivariate Cox regression analyses showed that $\mathrm{pT}$ stage, lymph node status, and EMP2 status were associated significantly with progression-free and cancer-specific survival, respectively (Table 1). Kaplan-Meier survival analysis showed significant differences in progression-free $(P=0.003)$ (Figure $3 \mathrm{~B})$ and cancer-specific survival $(P<0.001)$ (Figure $3 \mathrm{C})$ in relation to EMP2 expression. Taken together, our results suggest that loss of EMP2 expression is associated with progression of $\mathrm{UC}$, and that EMP2 may function as a suppressor in urothelial carcinogenesis.

\section{Cellular Localization of EMP2 and Effect on Cell Proliferation}

Because EMP2 was suggested to function as a tumor suppressor in UC, we then investigated the molecular basis of tumorigenesis. Because EMP2 appears on the plasma membrane and perinuclear area under fluorescence microscopy, we stained cells with an endoplasmic reticulum marker (ER-tracker) and examined their cellular localization in vivo using laser-scanning confocal microscopy. The analysis showed that EMP2 was localized predominantly on the plasma membrane and ER (Figure 4, A and B).
The effect of EMP2 on cell growth was analyzed using TSGH8301/GFP and TSGH8301/EMP2-2 stable cell lines. The growth of tumor cells was inhibited in cells that overexpressed EMP2 compared with control cells $(P<0.001$; two-way analysis of variance) (data not shown). The flow

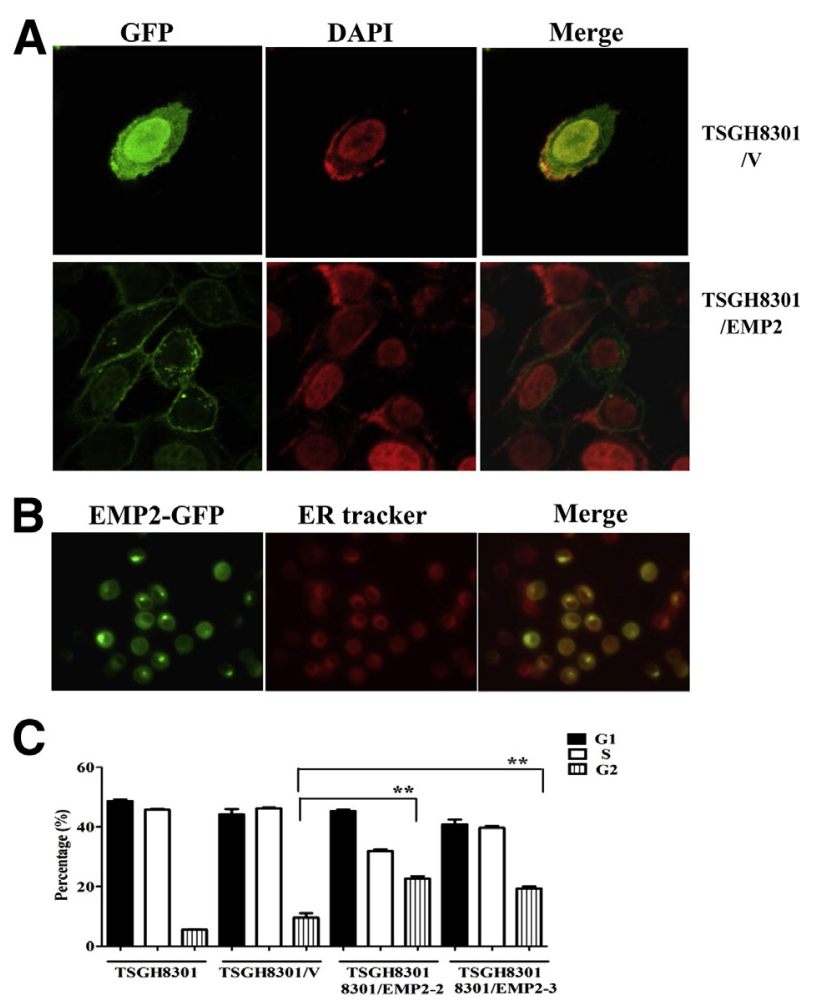

Figure 4 Subcellular localization of EMP2 and the effect of EMP2 on cell growth. A: TSGH8301/EMP2-2 cells stained with DAPI were analyzed using confocal microscopy (PL-AP0 $63 \times / 1.32$ oil). The green signal indicates the GFP or EMP2-GFP, and the red signal (DAPI) highlights the localization of nuclei. B: Cells stained with the endoplasmic reticulum marker (ER tracker). The green signal indicates EMP2-GFP, and the red signal indicates the location of ER. C: The cell-cycle distribution between parental and stable cell lines was assessed using flow cytometry. EMP2 overexpression induced an increase in the G2-M phase with a more apparent effect after serum starvation. There was a significant increase in the G2-M phase in stable cell lines that overexpressed EMP2 after 48 hours of serum starvation. ${ }^{*} P<0.01$. 

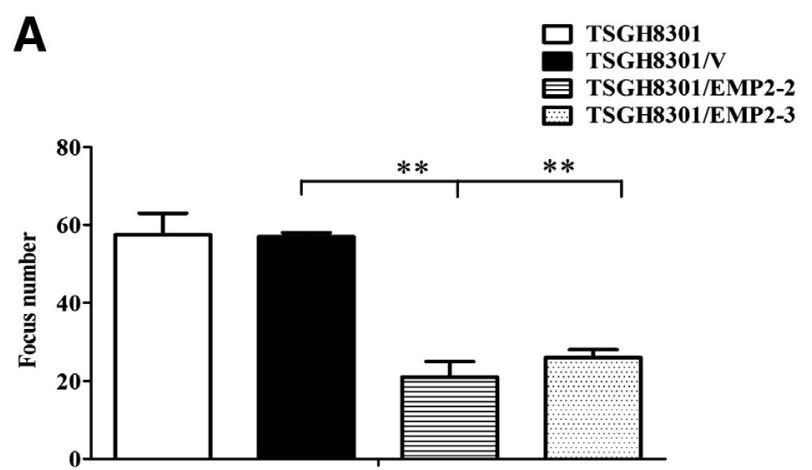

B

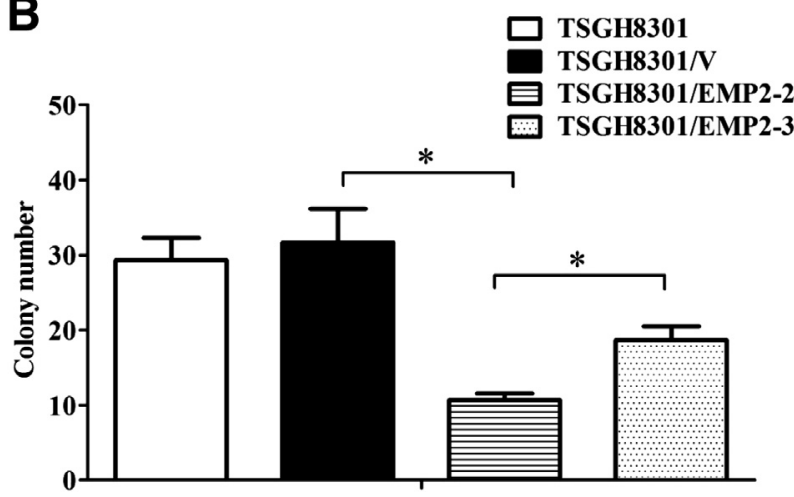

Figure 5 The foci formation and colony number in relation to EMP2 expression status. Cells $\left(2 \times 10^{2}\right)$ were plated in $10-\mathrm{cm}$ dishes and cultured. Colonies were stained with Giemsa and imaged after 14 days. A: The results of foci formation in each experimental group. The foci formation of TSGH8301/EMP2-2 and TSGH8301/EMP2-3 cells was significantly lower than TSGH8301/V cells. ${ }^{*} P<0.01$, paired Student's $t$-test. B: Cells $\left(3 \times 10^{3}\right)$ were plated in 6 -well trays and cultured in $0.35 \%$ agar containing serum. The number of colonies was counted after 14 days. Both TSGH8301/EMP2-2 and TSGH8301/EMP2-3 cells had a significantly lower number of colonies than TSGH8301/V cells. ${ }^{*} P<0.05$, paired Student's $t$-test. The number of TSGH8301/EMP2-2 colonies was significantly lower than of TSGH8301/ EMP2-3 colonies. ${ }^{*} P<0.05$, paired Student's $t$-test. The data for each group are means $\pm S D$ derived from three independent experiments.

cytometric analysis showed a significant increase of G2-M phase arrest in stable cell lines overexpressing EMP2 compared with controls $(P<0.01$; two-way analysis of variance) (Figure 4C). This result is consistent with our earlier report that soy isoflavones induced a G2-M cell-cycle arrest. $^{19}$ In addition, EMP2 overexpression appeared to induce increased staining of annexin $\mathrm{V}$ (a pro-apoptotic marker), but did not affect the double staining for annexin $\mathrm{V}$ and propidium iodide (late-stage apoptotic markers) (Supplemental Figure S2), despite the fact that EMP2 is related to apoptosis and cell death. . $^{9,11}$

\section{Significance of EMP2 on Foci Formation and Anchorage-Independent Growth}

The foci formation of TSGH8301/EMP2 cells was significantly lower than that of TSGH8301/V cells $(P<0.01$; paired Student's $t$-test), supporting its role as a tumor suppressor (Figure 5A). To verify this interpretation, the transfectants were tested for anchorage-independent growth using a soft agar assay. TSGH8301/EMP2 cells had significantly fewer colonies than did TSGH8301/V cells ( $P<0.05$; paired Student's $t$-test) (Figure 5B). The colonies also were smaller in TSGH8301/EMP2 cells.

\section{EMP2 Cross-Talk with Integrins in Modulation of Biological Effects}

Because EMP2 was reported to modify the expression of integrins (eg, $\alpha \mathrm{V}, \beta 1, \beta 3$ ) by altering their adhesion to extracellular matrix proteins, ${ }^{31}$ the expression of integrins was analyzed in relation to EMP2 status. We found that EMP2 increased the expression of both $\alpha \mathrm{V}$ and $\beta 3$ integrins in stable cell lines, which was confirmed using real-time PCR (Figure 6A).

To further verify the EMP2-related integrin partners, both TSGH8301 and TSGH8301/EMP2-2 stable cells were
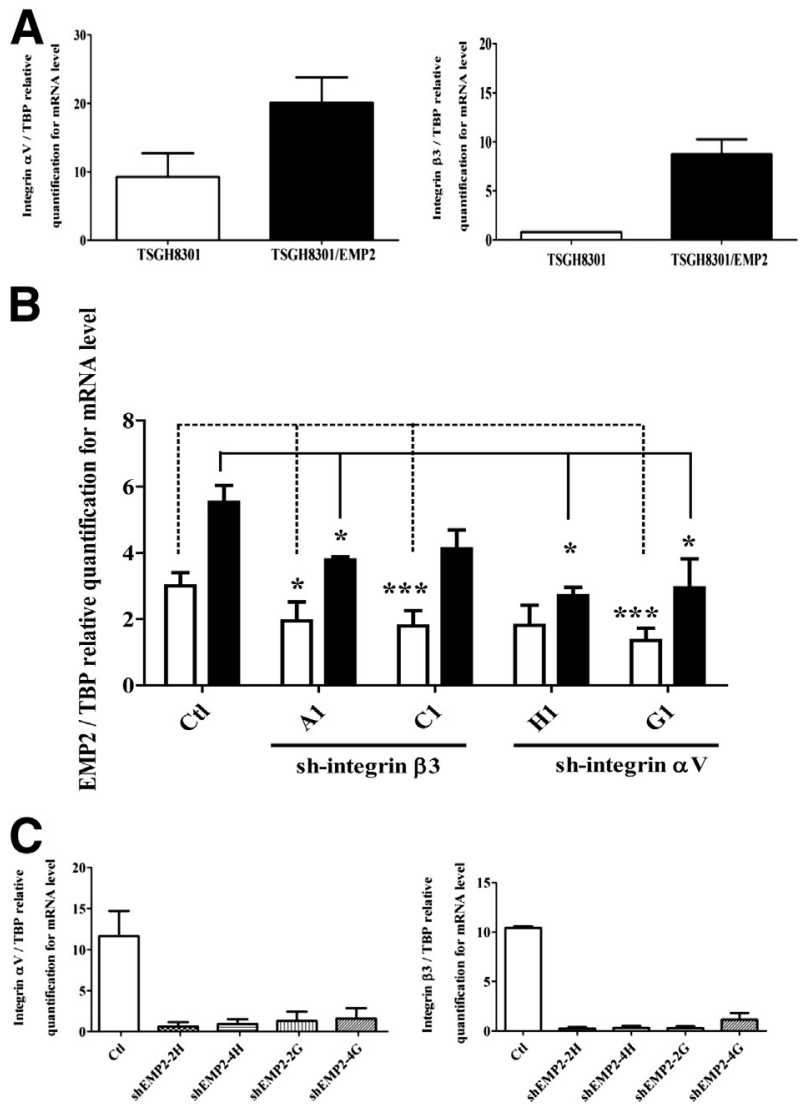

Figure 6 The cross-talk between EMP2 and integrins in modulation of cell adhesion and migration. A: Expression of integrins in relation to EMP2 status. Real-time PCR showed that EMP2 stimulates the expression of both $\alpha \mathrm{V}$ and $\beta 3$ integrins in stable cell lines. B: Effect of integrin knockdown on EMP2 expression. It showed that EMP2 was suppressed when TSGH8301 and TSGH8301/EMP2-2 stable cells were transfected with sh-integrin $\alpha \mathrm{V}$ (clone $\mathrm{H} 1$ and $\mathrm{G} 1$ ) or sh-integrin $\beta 3$ (clone $\mathrm{A} 1$ and $\mathrm{C} 1$ ). ${ }^{*} P<0.05,{ }^{* * *} P<0.001$, respectively, paired Student's $t$-test. C: Effect of EMP2 knockdown on integrin expression. When EMP2 was knocked down, expression of both integrin $\beta 3$ and $\alpha \mathrm{V}$ was suppressed $(P<0.001$ and $P<0.05$, respectively; one-way analysis of variance). Two independent clones were analyzed in each shRNA experiment (pSUPER-hEMP2-2/GFP, pSUPER-hEMP2-4/GFP, pSUPER-hEMP2-2/Hyg, pSUPER-hEMP2-4/Hyg). 
transfected with sh-integrin $\beta 3$ (clone $\mathrm{A} 1$ and $\mathrm{C} 1$ ) and shintegrin $\alpha \mathrm{V}$ (clone $\mathrm{H} 1$ and $\mathrm{G1}$ ) or shEMP2 RNA, respectively. EMP2 expression was suppressed when integrin was inhibited in cells treated with sh-integrin $\beta 3$ or sh-integrin $\alpha \mathrm{V}$, respectively (paired Student's $t$-test) (Figure 6B). In contrast, EMP2 knockdown suppressed integrin $\beta 3$ and $\alpha \mathrm{V}(P<0.001$ and $P<0.05$; one-way analysis of variance) (Figure 6C). These results support the notion that EMP2 and integrins $\alpha \mathrm{V}$ and $\beta 3$ synergistically modulate cell adhesion and migration in vitro. Whether they synergistically or competitively modulate cell adhesion and migration need to be clarified.

\section{Discussion}

We showed that expression of EMP2 is associated inversely with the malignant potential of uroepithelial cell lines, and could be activated by isoflavones in vitro. Reintroducing EMP2 in cancer cells induced a growth arrest in the G2/M phase, reduced anchorage-independent proliferation, and reduced focus formation. In addition, EMP2 overexpression significantly inhibited tumor growth in severe combined immunodeficiency mice. Down-regulated EMP2 is associated with muscle invasion of UUT-UC and with worse progression-free and cancer-specific survival. The characteristics of EMP2 fulfill the fundamental criteria of a tumorsuppressor gene.

Comparable findings also have been reported in several recent studies. EMP2 was down-regulated in profiling experiments of human lung adenocarcinoma, ${ }^{32}$ prostate cancer, ${ }^{33}$ and nasopharyngeal carcinoma. ${ }^{10}$ Higher levels of EMP2 were observed in grade I human gliomas versus grade II and grade IV tumors. ${ }^{34}$ EMP2 expression was significantly lower in node-positive tumors than in nodenegative cholangiocarcinoma. In addition, reduced expression of both TIMP3 and EMP2 may lead to increased cell migration and inhibition of cell-stromal interaction of cancer cells. ${ }^{35}$ Loss of EMP2 expression was correlated with advanced nasopharyngeal carcinoma, and is an independent prognosticator for worse disease-specific survival and local recurrence-free survival. ${ }^{10}$

However, it is controversial that EMP2 seems to function as an oncogene in human endometrial and ovarian cancers, ${ }^{12,13}$ and that it is a novel biomarker for preneoplastic lesions of endometrial cancer. Currently, we have no complete rationale to explain our paradoxic results that provide evidence in support of the notion that EMP2 is a tumor suppressor in urothelial cancer. In sharp contrast to urinary tract cancer, both endometrial and ovarian carcinomas are hormone-dependent cancers. Prior studies have shown that c-Myb is a possible estrogen-receptor target gene ${ }^{33}$ and that $E M P 2$ is a possible c-Myb target gene. ${ }^{36}$ Therefore, it is plausible to speculate that estrogen modulates the expression of EMP2, at least in part, through c-Myb. A detailed investigation is mandatory to clarify the estrogen-related signaling that modulates EMP2 expression and its biological activity.
In this study, we found no evidence of mutations or deletions in the exons or open reading frame of EMP2 in any of the uroepithelial cell lines tested (data not shown). Isoflavone-induced up-regulation of EMP2 promoter activity supports that EMP2 is a direct target of soy isoflavones in vivo. Because dietary genistein and related soy isoflavones reactivate methylation-silenced genes, ${ }^{37}$ it is possible that methylation is significant in the modulation of EMP2 expression. Alternatively, EMP2 is one of the EGR1 target genes in human prostate cancer. ${ }^{38}$ We have shown that genistein up-regulates EGR-1 in vitro. Expression of EMP2 thus also could be activated by isoflavones through EGR-1. ${ }^{27}$

For cell-matrix interaction, EMP2 controls the membranous expression of $\alpha 5 \beta 1$ and $\alpha 6 \beta 1$ integrins and class I major histocompatibility complex proteins. ${ }^{14}$ A recent knockdown experiment showed that EMP2 is important for blastocyst implantation in the uterine endometrium, in part through its direct association with and regulation of $\alpha \mathrm{V} \beta 3$ integrin. ${ }^{39} \mathrm{We}$ also found that EMP2 modulates $\alpha \mathrm{V} \beta 3$ integrin expression and interacts with the extracellular matrix. All of these findings suggest that EMP2 increases the cell adhesion of cancer cells through a synergistic regulation of integrins, especially integrin $\beta 3$ (data not shown). In addition, EMP2 reciprocally regulates the repertoire of $\alpha 6 \beta 1$ to $\alpha 5 \beta 1$ on the cell surface and increases its association with laminin. ${ }^{40}$ Taken together, all of the data imply that EMP2 is a multiconnector for integrin clustering and for their interaction with the extracellular matrix, thereby modulating cancer cell adhesion and migration.

Moreover, EMP2 may be a key regulator of cell membrane composition. A recent study showed that EMP2 downregulates caveolin-1, a negative regulator of membrane protein, by preventing its internalization. ${ }^{41}$ In human bladder cancer, expression of caveolin-1 is related positively to tumor progression. ${ }^{42}$ Expression of EMP2 was shown to drive the cellular response toward a FAK-dependent pathway. ${ }^{43}$ In addition, activation of the Src and FAK family members and downstream signaling proteins are associated with a good prognosis in UC of the bladder. ${ }^{44}$ As a result, we speculate that reciprocal regulation of EMP2 and caveolin-1 levels in cancer cells may reshape the cellular surface-receptor repertoire and its attendant responsiveness to the local environment. Additional experiments are required to verify that an EMP2-targeted approach may be an innovative strategy for cancer therapy.

In summary, EMP2 was identified as a novel tumorsuppressor gene in a model experiment using SSH profiling. EMP2 overexpression inhibits cancer cell proliferation, anchorage-independent growth in vitro, and xenograft tumorigenesis in severe combined immunodeficiency mice. Down-regulation of EMP2 is an important prognostic indicator in muscle-invasive UUT-UC. All of our data support that EMP2 is a tumor-suppressor gene in UC in vivo. EMP2 may be an innovative co-targeting candidate in the design of integrin-based cancer therapy. 


\section{Supplemental Data}

Supplemental material for this article can be found at http://dx.doi.org/j.ajpath.2013.05.015.

\section{References}

1. Jemal A, Siegel R, Xu J, Ward E: Cancer statistics. CA Cancer J Clin 2010, 60:277-300

2. Munoz JJ, Ellison LM: Upper tract urothelial neoplasms: incidence and survival during the last 2 decades. J Urol 2000, 164:1523-1525

3. Yang MH, Chen KK, Yen CC, Wang WS, Chang YH, Huang WJ, Fan FS, Chiou TJ, Liu JH, Chen PM: Unusually high incidence of upper urinary tract urothelial carcinoma in Taiwan. Urology 2002, 59: 681-687

4. Chromecki TF, Bensalah K, Remzi M, Verhoest G, Cha EK, Scherr DS, Novara G, Karakiewicz PI, Shariat SF: Prognostic factors for upper urinary tract urothelial carcinoma. Nat Rev Urol 2010, 8: 440-447

5. Stewart GD, Bariol SV, Grigor KM, Tolley DA, McNeill SA: A comparison of the pathology of transitional cell carcinoma of the bladder and upper urinary tract. BJU Int 2005, 95:791-793

6. Wadehra M, Sulur GG, Braun J, Gordon LK, Goodglick L: Epithelial membrane protein-2 is expressed in discrete anatomical regions of the eye. Exp Mol Pathol 2003, 74:106-112

7. Ben-Porath I, Kozak CA, Benvenisty N: Chromosomal mapping of Tmp (Emp1), Xmp (Emp2), and Ymp (Emp3), genes encoding membrane proteins related to Pmp22. Genomics 1998, 49:443-447

8. Attardi LD, Reczek EE, Cosmas C, Demicco EG, McCurrach ME, Lowe SW, Jacks T: PERP, an apoptosis-associated target of p53, is a novel member of the PMP-22/gas3 family. Genes Dev 2000, 14: 704-718

9. Wang CX, Wadehra M, Fisk BC, Goodglick L, Braun J: Epithelial membrane protein 2, a 4-transmembrane protein that suppresses B-cell lymphoma tumorigenicity. Blood 2001, 97: 3890-3895

10. Chen YH, Wu LC, Wu WR, Lin HJ, Lee SW, Lin CY, Chang SL, Chow NH, Huang HY, Li CF, Hsu HP, Shiue YL: Loss of epithelial membrane protein-2 expression confers an independent prognosticator in nasopharyngeal carcinoma: a cohort study. BMJ Open 2012, 2: e000900

11. Shimazaki K, Lepin EJ, Wei B, Nagy AK, Coulam CP, Mareninov S, Fu M, Wu AM, Marks JD, Braun J, Gordon LK, Wadehra M: Diabodies targeting epithelial membrane protein 2 reduce tumorigenicity of human endometrial cancer cell lines. Clin Cancer Res 2008, 14: 7367-7377

12. Fu M, Maresh EL, Soslow RA, Alavi M, Mah V, Zhou Q, Iasonos A, Goodglick L, Gordon LK, Braun J, Wadehra M: Epithelial membrane protein-2 is a novel therapeutic target in ovarian cancer. Clin Cancer Res 2010, 16:3954-3963

13. Habeeb O, Goodglick L, Soslow RA, Rao RG, Gordon LK, Schirripa O, Horvath S, Braun J, Seligson DB, Wadehra M: Epithelial membrane protein-2 expression is an early predictor of endometrial cancer development. Cancer 2010, 116:4718-4726

14. Wadehra M, Goodglick L, Braun J: The tetraspan protein EMP2 modulates the surface expression of caveolins and glycosylphosphatidyl inositol-linked proteins. Mol Biol Cell 2004, 15: 2073-2083

15. Wadehra M, Natarajan S, Seligson DB, Williams CJ, Hummer AJ, Hedvat C, Braun J, Soslow RA: Expression of epithelial membrane protein-2 is associated with endometrial adenocarcinoma of unfavorable outcome. Cancer 2006, 107:90-98

16. Chen C, Kong AN: Dietary cancer-chemopreventive compounds: from signaling and gene expression to pharmacological effects. Trends Pharmacol Sci 2005, 26:318-326
17. Banerjee S, Li Y, Wang Z, Sarkar FH: Multi-targeted therapy of cancer by genistein. Cancer Lett 2008, 269:226-242

18. Zhou JR, Mukherjee P, Gugger ET, Tanaka T, Blackburn GL, Clinton SK: Inhibition of murine bladder tumorigenesis by soy isoflavones via alterations in the cell cycle, apoptosis, and angiogenesis. Cancer Res 1998, 58:5231-5238

19. Su SJ, Yeh TM, Lei HY, Chow NH: The potential of soybean foods as a chemoprevention approach for human urinary tract cancer. Clin Cancer Res 2000, 6:230-236

20. Su SJ, Yeh TM, Chuang WJ, Ho CL, Chang KL, Cheng HL, Liu HS, Cheng HL, Hsu PY, Chow NH: The novel targets for anti-angiogenesis of genistein on human cancer cells. Biochem Pharmacol 2005, 69: 307-318

21. Chow NH, Sun Y, Liu HS, Su SJ, Yeh TM, Chuang WJ, Ho CL: Identification of molecular mechanisms of soy isoflavones-induced tumor suppressor effect on human bladder cancer. Proc Am Assoc Cancer Res 2001, 42:865

22. Yeh BW, Wu WJ, Li WM, Li CC, Huang CN, Kang WY, Liu ZM, Huang HS: Overexpression of TG-interacting factor is associated with worse prognosis in upper urinary tract urothelial carcinoma. Am J Pathol 2012, 181:1044-1055

23. Cheng L, Pan CX, Yang XJ, Lopez-Beltran A, MacLennan GT, Lin H, Kuzel TM, Papavero V, Tretiakova M, Nigro K, Koch MO, Eble JN: Small cell carcinoma of the urinary bladder: a clinicopathologic analysis of 64 patients. Cancer 2004, 101:957-962

24. Edge SB, Compton CC: The American Joint Committee on Cancer: the 7th edition of the AJCC cancer staging manual and the future of TNM. Ann Surg Oncol 2010, 17:1471-1474

25. Cheng HL, Trink B, Tzai TS, Liu HS, Chan SH, Ho CL, Sidransky D, Chow NH: Overexpression of c-met as a prognostic indicator for transitional cell carcinoma of the urinary bladder: a comparison with p53 nuclear accumulation. J Clin Oncol 2002, 20:1544-1550

26. Ju YH, Doerge DR, Allred KF, Allred CD, Helferich WG: Dietary genistein negates the inhibitory effect of tamoxifen on growth of estrogen-dependent human breast cancer (MCF-7) cells implanted in athymic mice. Cancer Res 2002, 62:2474-2477

27. Chen CC, Shieh B, Jin YT, Liau YE, Huang CH, Liou JT, Wu LW, Huang W, Young KC, Lai MD, Liu HS, Li C: Microarray profiling of gene expression patterns in bladder tumor cells treated with genistein. J Biomed Sci 2001, 8:214-222

28. Azarova AM, Lin RK, Tsai YC, Liu LF, Lin CP, Lyu YL: Genistein induces topoisomerase IIbeta- and proteasome-mediated DNA sequence rearrangements: implications in infant leukemia. Biochem Biophys Res Commun 2010, 399:66-71

29. Gann PH, Kazer R, Chatterton R, Gapstur S, Thedford K, Helenowski I, Giovanazzi S, Van Horn L: Sequential, randomized trial of a low-fat, high-fiber diet and soy supplementation: effects on circulating IGF-I and its binding proteins in premenopausal women. Int J Cancer 2005, 116:297-303

30. Vinall RL, Hwa K, Ghosh P, Pan CX, Lara PN Jr, de Vere White RW: Combination treatment of prostate cancer cell lines with bioactive soy isoflavones and perifosine causes increased growth arrest and/or apoptosis. Clin Cancer Res 2007, 13:6204-6216

31. Wadehra $M$, Dayal $M$, Mainigi $M$, Ord $T$, Iyer $R$, Braun $J$, Williams CJ: Knockdown of the tetraspan protein epithelial membrane protein-2 inhibits implantation in the mouse. Dev Biol 2006, 292 430-441

32. Powell CA, Spira A, Derti A, DeLisi C, Liu G, Borczuk A, Busch S, Sahasrabudhe S, Chen Y, Sugarbaker D, Bueno R, Richards WG, Brody JS: Gene expression in lung adenocarcinomas of smokers and nonsmokers. Am J Respir Cell Mol Biol 2003, 29:157-162

33. Tomlins SA, Mehra R, Rhodes DR, Cao X, Wang L, Dhanasekaran SM, Kalyana-Sundaram S, Wei JT, Rubin MA, Pienta KJ, Shah RB, Chinnaiyan AM: Integrative molecular concept modeling of prostate cancer progression. Nat Genet 2007, 39:41-51

34. Rickman DS, Bobek MP, Misek DE, Kuick R, Blaivas M, Kurnit DM, Taylor J, Hanash SM: Distinctive molecular profiles of high-grade and 
low-grade gliomas based on oligonucleotide microarray analysis. Cancer Res 2001, 61:6885-6891

35. Obama K, Ura K, Li M, Katagiri T, Tsunoda T, Nomura A, Satoh S, Nakamura Y, Furukawa Y: Genome-wide analysis of gene expression in human intrahepatic cholangiocarcinoma. Hepatology 2005, 41:1339-1348

36. Lei W, Rushton JJ, Davis LM, Liu F, Ness SA: Positive and negative determinants of target gene specificity in myb transcription factors. J Biol Chem 2004, 279:29519-29527

37. Fang MZ, Chen D, Sun Y, Jin Z, Christman JK, Yang CS: Reversal of hypermethylation and reactivation of p16INK4a, RARbeta, and MGMT genes by genistein and other isoflavones from soy. Clin Cancer Res 2005, 11:7033-7041

38. Svaren J, Ehrig T, Abdulkadir SA, Ehrengruber MU, Watson MA, Milbrandt J: EGR1 target genes in prostate carcinoma cells identified by microarray analysis. J Biol Chem 2000, 275:38524-38531

39. Wadehra M, Forbes A, Pushkarna N, Goodglick L, Gordon LK, Williams CJ, Braun J: Epithelial membrane protein-2 regulates surface expression of alphavbeta3 integrin in the endometrium. Dev Biol 2005, 287:336-345
40. Wadehra M, Iyer R, Goodglick L, Braun J: The tetraspan protein epithelial membrane protein-2 interacts with betal integrins and regulates adhesion. J Biol Chem 2002, 277:41094-41100

41. Forbes A, Wadehra M, Mareninov S, Morales S, Shimazaki K, Gordon LK, Braun J: The tetraspan protein EMP2 regulates expression of caveolin-1. J Biol Chem 2007, 282:26542-26551

42. Thomas S, Overdevest JB, Nitz MD, Williams PD, Owens CR, Sanchez-Carbayo M, Frierson HF, Schwartz MA, Theodorescu D: Src and caveolin-1 reciprocally regulate metastasis via a common downstream signaling pathway in bladder cancer. Cancer Res 2011, 71:832-841

43. Morales SA, Telander DG, Mareninov S, Nagy A, Wadehra M, Braun J, Gordon LK: Anti-EMP2 diabody blocks epithelial membrane protein 2 (EMP2) and FAK mediated collagen gel contraction in ARPE-19 cells. Exp Eye Res 2012, 102:10-16

44. Qayyum T, Fyffe G, Duncan M, McArdle PA, Hilmy M, Orange C, Halbert G, Seywright M, Horgan PG, Underwood MA, Edwards J: The interrelationships between Src, Cav-1 and RhoGD12 in transitional cell carcinoma of the bladder. Br J Cancer 2012, 106:1187-1195 